\title{
Frequency of Achilles Tendonitis in Obese Patients
}

\author{
Sheeza Iftikhar*, Sana Batool, Ashfaq Ahmad, Faiza Sharif and Khansa Ghaffar \\ Allied Health Sciences, Department UIPT, Pakistan
}

*Corresponding author: Sheeza Iftikhar, ed Health Sciences, Department UIPT, University of Lahore, Lahore, Pakistan

\begin{abstract}
ARTICLE INFO
Received: 幽 February 11, 2020

Published: 蔧 February 20, 2020

Citation: Sheeza Iftikhar, Sana Batool, Ashfaq Ahmad, Faiza Sharif, Khansa Ghaffar. Frequency of Achilles Tendonitis in Obese

\section{ABSTRACT}

Background: Achilles Tendonitis discomforts signify difficulties of walking and running. Achilles tendon is the thickest and longest tendon of human body that holds the maximum mechanical stress of human body. High Body mass Index (BMI) causes the increase in mechanical stress on Achilles tendon that results into an inflamed tendon. Achilles Tendonitis complaints are significant throughout many obese patients. Obese and old patients are mostly vulnerable to Achilles Tendonitis. Increase in BMI causes pressure at planter fascia that increases its symptoms.
\end{abstract} Patients. Biomed J Sci \& Tech Res 25(5)2020. BJSTR. MS.ID.004261.

Keywords: Frequency; Obese Patients; BMI (body Mass Index)

Objective: The objective of the study was to determine the Frequency of Achilles tendonitis in obese patients.

Methods: A cross sectional study was conducted and a standardized questionnaire (VISA A questionnaire) for Achilles tendonitis was used to collect the data by using the non-probability convenient technique. Data was collected from Bahria International hospital and University of Lahore (UOL) teaching hospital. It was collected through sample size of 126 obese patients. SPSS version 25.0 was used for data analysis.

Results: According to the results of conducted study, about 11(8.7\%) patients had Achilles tendonitis. 52(41.3\%) patients had moderate pain. While, 63(50.0\%) of individuals had mild or no pain. In this study the number of males is 55(43.7\%) and females are $71(56.3 \%)$.

Conclusion: This study concluded that the frequency of Achilles tendonitis in obese patients is very low (8.7\%). However, the reason of Achilles tendonitis is multifactorial including both intrinsic and extrinsic factors. High BMI (body mass index) is an intrinsic factor that induce pressure at planter fascia that increases its symptoms.

\section{Introduction}

Achilles tendon is the strongest and the largest tendon of human body. It has the maximum capacity to withstand the tensional forces while movement [1]. The Achilles tendon injuries are common among athletes and general population. The tendinous part of gastrocnemius and soleus muscles combines to form Achilles tendon [2]. The prevalence of Achilles tendonitis in Dutch GP registered patients is 1.8 per 1000.In fully grown up people the prevalence rate is 2.35 per 1000 . The $35 \%$ of sports related person were recorded with the problem [3]. The incidence of lower extremity tendonitis according to Dutch study is 11.83 and 10.52 per 1000 person per years [4]. According to the research conducted in US about $50 \%$ of distance runners have incidence of Achilles tendon pathology in their lifetime [5]. About 7\% of Asian adults till the age of 65 have incidence of Achilles tendonitis with
$10 \%$ incidence of developing it throughout lifetime [6]. Achilles tendonitis is a collective reason of ill health. In this disease the degeneration of collagen fibers occurs which cause weakening of Achilles tendon which may results into rupture of collagen fibers leading to an increased mechanical stress on tendon leading it into unstable tendon [7].

Achilles tendonitis effects many sports person and cause many structural and functional problems in them. Obvious signs of tendon damage are seen in them [8]. Achilles tendonitis leads to pain with inflammation in the calcaneal bursa and at the surface of Achilles tendon anteriorly resulting into mechanical irritation, which may leads to Achilles tendonitis. Sometimes it may lead to pain, swelling, and limitation of activities of daily life [9]. The risk factors of Achilles tendonitis include overuse causing trauma, 
less vascularization of tissues and in combination with extremity mechanical imbalance [10]. There are numerous reasons that cause pain but most obvious reasons are extrinsic and intrinsic reasons. Extrinsic reasons are related to any hormone therapy, extreme physical activities. While, intrinsic reasons are related to any pathology such as diabetes, obesity or any genetic cause [11]. Obesity is considered as one of the risk factor of Achilles tendonitis. Increase in Body mass exerts greater pressure at Achilles tendon as it is the tendon that holds the maximum load of human body [12]. Body Mass Index (BMI) is a measuring scale that is used to measure the obesity level in an individual. Individuals with body mass index greater than 30 are considered as obese patients, individuals with body mass index (BMI) from 18 to 25 is normal, the person greater than 24 to 30 is in overweight category while less than $18 \mathrm{BMI}$ is considered underweight [13].

The association of sex, Body Mass Index was studied with tendon stiffness of lower extremity [14]. According to study conducted in 2016 the athletes with posterior heel pain were reported as obese later they studied patients of obese patients having Achilles Tendinosis. Calcaneal exostosis and Haglund's deformity with debridement of the degenerative tissue of the tendon were stated as obese [15]. In Past few years the proofs has arisen to defend the possible correlation between increased BMI and vulnerability to tendinopathy. The best evidences were found that proved that obesity is a risk factor of developing Achilles Tendonitis [16]. Achilles tendonitis is reported in people who are involved in walking and running sports. However, a little research was made to determine the incidence of Achilles tendonitis in obese patients which is an important risk factor of developing the disease [17]. The aim of present study is to determine the frequency of Achilles tendonitis in obese patients. The study provides the awareness about how increase in Body Mass Index (BMI) increases the stress at Achilles tendon leading to Achilles tendonitis.

\section{Materials and Methods}

This cross-sectional study was conducted on 126 obese patients in which 55(43.7\%) were males and 71(56.3\%) were females. The non-probability convenient technique was used in this study. The settings were Bahria International Hospital and University of Lahore (UOL) Teaching Hospital. Study duration was four months. Sample selection includes obese patients, Both Genders, Individuals with 10 to 85 years of age, with BMI from 30 to 50. The Individuals with any fracture or injury, with BMI less than 30 and diabetic patients are in exclusion criteria. A standardized questionnaire (VISA A questionnaire) was used with modification of demographics (age, gender, weight and height) to collect data. Weight and height provided a proper measure of BMI (Body Mass Index). Data was analyzed by SPSS version 25.0. Total 129 participants were asked to fill the questionnaire in this study. Total 126 questionnaires were filled with response rate of $85.4 \%$. Part one of the questionnaire was about the demographic data which includes the age, gender, height, and weight and their commutative BMI (Body Mass Index).

Patients with BMI in between the range of 30 to 50 were asked to fill a standardized questionnaire (VISA A questionnaire). In this questionnaire the pain scales are given in each of the question with scoring, on the basis of this scoring the patient was categorized into severe, mild or moderate pain scale. The frequency of male is $55(43.7 \%)$ and the frequency of female is $71(56.3 \%)$. In the descriptive statistics of age, there are five frequencies in this table in between 10-85. It provides the descriptive statistics of BMI (Body Mass Index) with four frequencies with ranges in between 30-50. (Table 1) also provide the total scoring of pain according to VISA A questionnaire. On the basis of this scoring the frequency of Achilles tendonitis in Obese patients was determined which is about $11(8.7 \%), 52(41.3 \%)$ of patients had moderate level of pain sometimes and $63(50.0 \%)$ of patients had mild or no pain (Figure 1 ).

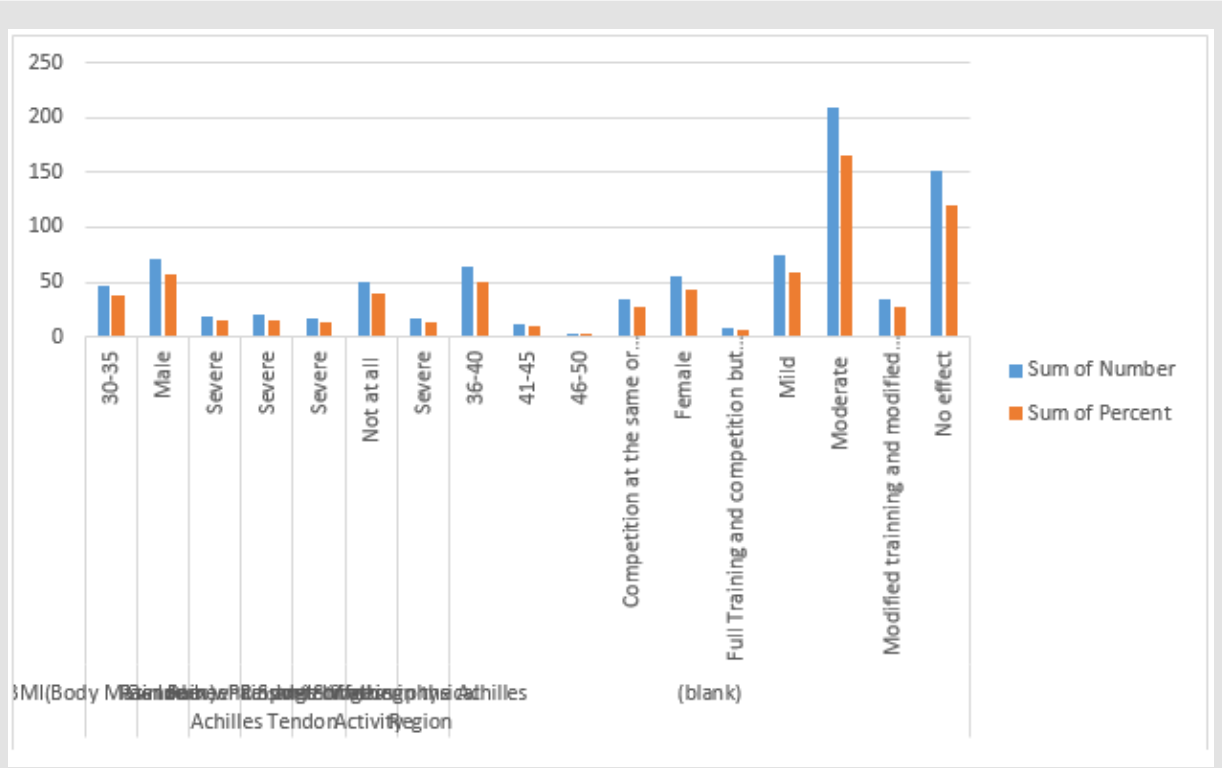

Figure 1. 
Table 1.

\begin{tabular}{|c|c|c|c|}
\hline Variable & Construct & Number & Percentage \\
\hline \multirow{2}{*}{ Gender } & Female & 71 & $56.30 \%$ \\
\hline & Male & 55 & $43.70 \%$ \\
\hline \multirow[t]{4}{*}{ BMI(Body Mass Index) } & $30-35$ & 47 & $37.30 \%$ \\
\hline & $36-40$ & 64 & $50.80 \%$ \\
\hline & $41-45$ & 12 & $9.50 \%$ \\
\hline & $46-50$ & 3 & $2.40 \%$ \\
\hline \multirow[t]{4}{*}{$\begin{array}{l}\text { Sports or other Physical } \\
\text { Activity }\end{array}$} & Not at all & 50 & $39.70 \%$ \\
\hline & Modified Training and modified competition & 34 & $27.00 \%$ \\
\hline & $\begin{array}{l}\text { Full training and competition but not at the same level as when } \\
\text { symptoms begin }\end{array}$ & 8 & $6.30 \%$ \\
\hline & Competing at the same or higher levels when symptoms begin & 34 & $27.00 \%$ \\
\hline \multirow[t]{4}{*}{$\begin{array}{l}\text { Stiffness in the Achilles } \\
\text { Region }\end{array}$} & Severe & 16 & $12.50 \%$ \\
\hline & Moderate & 55 & $43.70 \%$ \\
\hline & Mild & 17 & $13.50 \%$ \\
\hline & No Effect & 38 & $30.20 \%$ \\
\hline \multirow[t]{4}{*}{$\begin{array}{l}\text { Pain While Stretching } \\
\text { Achilles Achilles Tendon }\end{array}$} & Severe & 20 & $15.90 \%$ \\
\hline & Moderate & 46 & $36.50 \%$ \\
\hline & Mild & 22 & $17.50 \%$ \\
\hline & No Effect & 38 & $30.20 \%$ \\
\hline \multirow[t]{4}{*}{ Pain while walking } & Severe & 16 & $12.70 \%$ \\
\hline & Moderate & 55 & $43.70 \%$ \\
\hline & Mild & 17 & $13.50 \%$ \\
\hline & No Effect & 38 & $30.20 \%$ \\
\hline \multirow[t]{4}{*}{ Pain On heel Raising } & Severe & 18 & $14.30 \%$ \\
\hline & Moderate & 53 & $42.10 \%$ \\
\hline & Mild & 18 & $14.30 \%$ \\
\hline & No Effect & 37 & $29.40 \%$ \\
\hline
\end{tabular}

\section{Results and Discussion}

In a study conducted to determine the frequency of Achilles tendonitis in obese patients was a cross sectional study. The obese patients from Bahria International Hospital and UOL teaching Hospital were asked to fill a standardized questionnaire (VISA A questionnaire). About 126 obese patients of age limit from 10 to 85 'were asked to fill a standardized questionnaire. The obesity level was calculated by BMI (body Mass Index) calculator. The patients having BMI from 30 to 50 were asked to complete the survey, 55 (43.7\%) were males and 71 (56.3\%) were females' BMI was calculated by taking their weight in $\mathrm{kg} / \mathrm{m}$ and height in feet and inches. In the previous studies the researchers investigated that the obese patients develop Achilles tendonitis, but age is a very important factor.

The obese patient of an older age has high risk of developing Achilles tendonitis. Furthermore, studies can be accompanied for determining the Achilles Tendonitis in obese Patients with old age. About $8.7 \%$ obese patients were diagnosed with Achilles tendinitis, while $41.3 \%$ of obese patients had moderate pain and rest of $50 \%$ had mild or no pain. Erin Klein, in 2013 at Chicago studied that Achilles Tendonitis is highly correlated to Body Mass Index. It is considered as a risk factor for the development of Achilles tendonitis. Body Mass Index has a high impact on development and management of Achilles tendonitis. Achilles Tendonitis is a very common problem because it tolerates the maximum mechanical stress and load exerted by a human body. In Erin's study it was clear that the risk factor of developing Achilles tendonitis is based on multiple factors but inherent feature is the main reason In inherent feature body mass index (BMI) is most important feature because being obese implicate a double pressure on the tendon and it increases the mechanical stress and is the reason of excessive load causing the inflammation of tendon.

BMI is the best scale used to sum the obesity of population [18]. From the results of the study it was concluded that the patients having high Body Mass Index developed Achilles Tendonitis. Obese patients develop more problems related to Achilles tendon. Giada 
studied in 2011 in Australia that the adaptable factor of tendinopathy is adiposity, the study was conducted on 298 individuals. Males of an older age established Achilles tendon pathology and they had central fat distribution [19]. In the previous studies there are clear evidences that proves that increase in BMI (Body Mass Index) causes increase in mechanical stress on Achilles tendon leading to Achilles tendonitis and tendinosis. The obesity is considered as a risk factor of the development of Achilles tendonitis. The obesity is a genetic factor that leads to many pathologies in adulthood, the ankle and foot pathologies are most common that occur in a genetically inherited obese patient. As overweight increases the workload on Achilles tendon leading to weakness of the tendon and results into tendonitis.

The vulnerability of Achilles tendonitis is high in diabetic, obese and old patients. In this study the evidences of previous studies were used to find out the frequency of Achilles tendon inflammation in obese patients. The purpose of the study was to provide a clear idea about the relationship between Achilles tendon pathologies with increased body mass. This was a cross sectional study in which non-probability convenient technique as used. The frequency was $8.7 \%$ of Achilles tendonitis in obese patients which is very low but, still furthermore studies can be made with large sample size at different settings of Lahore Pakistan to provide a strong evidence of this research.

\section{Conclusion}

This study concluded that the frequency of Achilles tendonitis in obese patients present in Bahria International Hospital and University of Lahore (UOL) Teaching Hospital is very low that is about $11(8.7 \%)$. Moderate level of pain was present in 52 (41.3\%) of cases while $63(50.0 \%)$ of individuals had mild or no pain .However there is an association between increased body mass index and mechanical stress on Achilles tendon, because it is the most largest and thickest tendon that have maximum mechanical stress when body mass increases, with increase in body mass the load over tendon also increases and it weakens, resulting into tendonitis or tendinopathy of Achilles tendon.

\section{References}

1. Doral MN, Alam M, Bozkurt M, Turhan E, Atay OA, et al. (2010) Functional anatomy of the Achilles tendon. Knee Surgery, Sports Traumatology, Arthroscopy 18(5): 638-643.

2. Fornage BD (2011) Achilles tendon: US examination. Radiology 59(3): 759-764.

3. De Jonge S, Van den Berg C, De Vos R, Van Der Heide H, Weir A, et al (2011) Incidence of midportion Achilles tendinopathy in the general population. Br J Sports Med 45(13): 1026-1028.
4. Albers IS, Zwerver J, Diercks RL, Dekker JH, Van den Akker-Scheek I (2016) Incidence and prevalence of lower extremity tendinopathy in a Dutch general practice population: a cross sectional study. BMC musculoskeletal disorders 17(1): 16.

5. Lieberthal K, Paterson KL, Cook J, Kiss Z, Girdwood M (2019) Prevalence and factors associated with asymptomatic Achilles tendon pathology in male distance runners. Physical Therapy in Sport 39: 64-68.

6. Joshvaghan HG, Omidi-Kashani F (2018) Plantar Fasciitis Risk Factorsin Normal Population. Biosciences Biotechnology Research Asia 15(2): 427-430.

7. Hullfish TJ, Hagan KL, Casey E, Baxter JR (2018) Achilles Tendon Structure Differs Between Runners and Non-Runners Despite No Clinical Signs Or Symptoms Of Mid-Substance Tendinopathy. BioRxiv pp. 290866.

8. Hullfish TJ, Hagan KL, Casey E, Baxter JR (2018) Achilles tendon structure differs between competitive distance runners and nonrunners despite no clinical signs or symptoms of midsubstance tendinopathy. Journal of Applied Physiology 125(2): 453-458.

9. Duthon VB, Lubbeke A, Duc SR, Stern R, Assal M (2011) Noninsertional Achilles tendinopathy treated with gastrocnemius lengthening. Foot \& ankle international 32(4): 375-379.

10. Singh A, Calafi A, Diefenbach C, Kreulen C, Giza E (2017) Noninsertional tendinopathy of the Achilles. Foot and ankle clinics 22(4): 745-60.

11. Stephenson M (2015) Causation and risk factors of Achilles Tendinopathy.

12. Maffulli N, Via AG, Oliva F (2016) Achilles tendinopathy. The Lower Limb Tendinopathies: Springer pp. 149-164.

13. Locke AE, Kahali B, Berndt SI, Justice AE, Pers TH, et al. (2015) Genetic studies of body mass index yield new insights for obesity biology. Nature 518(7538): 197-206

14. Taş S, Yllmaz S, Onur MR, Soylu AR, Altuntaş O (2017) Patellar tendon mechanical properties change with gender, body mass index and quadriceps femoris muscle strength. Acta orthopaedica et traumatologica turcica 51(1): 54-59.

15. Mineta K, Suzue N, Matsuura T, Sairyo K (2016) Efficacy of Achilles Suture Bridge Technique for Insertional Achilles Tendinosis in an Obese and Athletic Patient. The journal of medical investigation JMI 63(3-4): 310-314.

16. Franceschi F, Papalia R, Paciotti M, Franceschetti E, Di Martino A, et al. (2014) Obesity as a risk factor for tendinopathy: a systematic review. Int J Endocrinol pp. 670262.

17. Kozlovskaia M, Vlahovich N, Ashton KJ, Hughes DC (2017) Biomedical Risk Factors of Achilles Tendinopathy in Physically Active People: a Systematic Review. Sports medicine open 3(1): 20.

18. Klein EE, Weil Jr L, Weil Sr LS, Fleischer AE (2013) Body mass index and achilles tendonitis: a 10-year retrospective analysis. Foot \& ankle specialist 6(4): 276-282.

19. Gaida JE, Alfredson H, Kiss ZS, Bass SL, Cook JL (2010) Asymptomatic Achilles tendon pathology is associated with a central fat distribution in men and a peripheral fat distribution in women: a cross sectional study of 298 individuals. BMC musculoskeletal disorders 11(1): 41. 
ISSN: 2574-1241

DOI: 10.26717/BJSTR.2020.25.004261

Sheeza Iftikhar. Biomed J Sci \& Tech Res

(c) (P) This work is licensed under Creative BY Commons Attribution 4.0 License

Submission Link: https://biomedres.us/submit-manuscript.php

$\begin{array}{ll}\text { BIOMEDICAL } & \text { Assets of Publishing with us } \\ \text { RESEARCHES } & \text { - Global archiving of articles } \\ & \text { - Immediate, unrestricted online access } \\ & \text { - Rigorous Peer Review Process } \\ & \text { - Anttps://biomedres.us/ }\end{array}$

